\title{
The Effects of Preschoolers' Oppositional Defiant Behavior Problem Trajectory on Parental Stress and on the Preschoolers' Self-control
}

\author{
Soo Jung Kim, Ick-Joong Chung \\ Department of Social Welfare, Ewha Womans University, Seoul, Korea \\ 유아의 반항성 행동 문제 발달 궤적이 \\ 부모의 양육스트레스와 유아의 자아통제에 미치는 영향
}

김수정, 정익중

이화여자대학교 사회복지학과

Objective: The purpose of this study is to investigate the effects of the preschoolers' oppositional defiant behavior problem trajectory on parental stress and on the preschoolers' self-control.

Methods: We used data from the 5th to 7th waves of the Panel Study on Korean Children(PSKC), and analyzed 1,703 4-year-old children, 1,662 5-year-old children, and 6-year-old 1,620 children, utilizing latent growth curve modeling.

Results and Conclusion: The results of this study were as follows. First, there were individual differences in the children's oppositional defiant behavior problems at age 4, and those behavioral problems tended to decrease overall as age increased. Second, the intercept of the children's oppositional defiant behavior problems at age 4 had a negative effect on parental stress and on preschoolers' self-control when they were 6 years old. In addition, the slope of the oppositional defiant behavior problem also had a significant effect on the increase of parental stress and on the decrease of the self-control. Based on these results, early diagnosis of oppositional defiant behavior problem is more important than any other factor. This study also suggests that immediate intervention and treatment are needed for preschoolers with oppositional defiant behavior problems, as well as their parents. In addition, plans should be implemented to raise preschoolers' self-control.

Keywords: Panel Study on Korean Children (PSKC), oppositional defiant behavior problems, development trajectory, parenting stress, self-control$$
\text { 서론 }
$$

영유아의 반항적 행동 문제는 부모나 유아교육기관의 교사가 가장 지도하기 어려운 문제 행동 중의 하나이다. 반항적 행동 문제는 안정적으로 영아 시기부터 시작될 수 있으며 학령기 까지 지속 될 수 있는데 부모, 교사, 또래 관계 등에 부정적인

Corresponding Author: Ick-Joong Chung, Department of Social Welfare, Ewha Womans University, 52 Ewhayeodae-gil, Seodaemun-gu, Seoul 03760, Korea

E-mail: ichung@ewha.ac.kr
\end{abstract}

영향을 미친다 (Broidy et al., 2003; Harvey, Friedman-Weieneth, Golstein \& Sherman, 2007; Petitclerc, Boivin, Dionne, Zoccolillo \& Trembly, 2009). 만일 반항적 행동 문제가 제대로 치료되지 않는다면 성장과정에서 반항성 행동장애, 품행 장애, 비행, 범 죄 등 보다 심각한 문제로 이어져 학업적 또는 사회적으로 심 각한 결과를 초래할 수 있으므로 조기에 발견하여 개입하는

(C)The Korean Association of Child Studies

This is an Open Access article distributed under the terms of the Creative Commons Attribution Non-Commercial License (http:// creativecommons.org/licenses/by-nc/4.0) which permits unrestricted noncommercial use, distribution, and reproduction in any medium, provided the original work is properly cited. 
것이 필요하다.

특히 영유아 시기와 같이 이른 시기의 발병은 아동기나 청 소년기에 발병한 것에 비해 더욱 심각하면서도 장기적인 문 제와 더불어 부족한 발달 결과를 예측하게 한다(Loeber, Burke, Lahey, Winters, \& Zera, 2000). 개인적 측면에서 문제가 되기 도 하지만 경제적인 측면에서도 3-8세 시기의 심각한 품행 문 제에 대한 연간 비용이 가족에게 상당한 부담을 줄 수 있다 (Romeo, Knapp, \& Scott, 2006). 이러한 측면에서 반항성 행동 문제는 영유아시기에 조기 발견하여 즉각적인 개입을 해 주는 것이 장기적인 관점에 비추어 볼 때 보다 효과적이라고 볼 수 있다.

반항성 행동 문제의 조기 발견은 무엇보다 중요하지만 정 상적인 발달과정과 행동 문제를 신중히 구분하는 것은 반드시 필요하다. American Academy of Child and Adolescent Psychiatry (2011)는 모든 아동들은 피곤할 때, 배고플 때, 스트레스를 받 거나, 화가 났을 때 반항 행동을 보이는 경우가 종종 있는데 이는 만 2-3세 아동이나 초기 청소년기에 자주 나타나는 정 상적인 발달 과정 중 하나일 경우도 많다고 언급하였다. 그러 나 드러내 놓고 하는 비협조적이고 적대적인 행동이 같은 나 이 또래 아동과 비교해서 자주 지속적으로 나타나고, 그런 행 동 때문에 아동의 사회, 가족, 학업 생활에 영향을 주는 경우에 는 심각한 염려를 해야 한다고 하였다. 이와 관련해 American Psychiatric Association (2013)의 DSM-5 (The Diagnostic and Statistical Manual of Mental Disorders, Fifth Edition)에서는 반항 성 행동 장애를 나이에 적합하지 않은 거부, 적대감, 시비조의 행동 양상이 최소 6개월 지속되는 파괴적 행동 장애(Disruptive Behavior Disorders [DBD])의 한 유형으로 규정하고 있다. 또 한 반항성 행동 장애의 경우, 뚜렷하게 반항적이고, 불복종적 이며, 도발적인 행동을 하지만 품행장애와는 달리 규칙을 어 기거나 타인의 권리를 침해하는 반사회적 행동이나 공격적인 행동을 두드러지게 나타나지 않는 특징이 있다고 하였다. 하 지만 이러한 특징들이 보인다고 할지라도 DSM-5에서는 반항 성 행동 장애의 진단평가에 대하여 임상적 인터뷰, 심리평가, 부모면담 등 다양한 진단평가도구 뿐 아니라 역기능적인 환 경에 대한 평가까지를 포함하는 것이 필요하다고 제안하였다 (American Psychiatric Association, 2013).

한편, 최근에는 패널자료의 확대에 힘입어 종단적 연구 설 계에 기초한 발달 궤적에 관한 연구(Nagin \& Trembly, 1999)가 진행되고 있다. 이는 연령이 높아짐에 따라 반항성 행동 문제 가 어떠한 양상으로 변화하는지 검증할 수 있으며 행동이 감 소하거나 증가하는 특정 시기를 확인할 수 있어 반항성 행동
문제의 변화를 이해할 수 있게 한다. 또한 초기 시점에서 시간 이 흐른 뒤 여러 시점을 살펴보는 종단 연구는 인과 관계의 방 향을 살펴보는데 제한이 있는 횡단 연구와는 달리 반항성 행 동 문제의 원인과 결과를 파악하는데 도움이 된다. 특히 발달 시기에 따른 반항성 문제 행동의 변화 양상과 개인차를 식별 하고 적절한 치료 및 예방을 설계하는데 유용하다고 볼 수 있 다(Ezpeleta et al., 2014).

이러한 반항성 행동 문제의 발달 궤적에 관한 연구는 두 가지 접근 방식으로 구분되는데 하나는 변수중심적 접근 (variable-centered approaches) 방식이고 다른 하나는 대상중심 적 접근(person-centered approaches) 방식이다(Chung, 2000). 먼저, 변수중심적 접근 방식은 초기 시점과 그 시점 이후 연 령이 증가에 따른 행동 발달의 평균적인 변화율을 살펴봄으 로써 발달이 특정 연령 시기에만 발현되는 것인지 또는 연령 이 증가함에 따라 행동의 변화 양상을 살펴 볼 수 있는 방법 이다(Kofler, Larsen, Sarver, \& Tolan, 2015; Leve, Kim, \& Pears, 2005). 이와 관련하여 Leadbeater, Thompson과 Gruppuso (2012) 의 연구에서는 12-18세 662명을 대상으로 잠재성장모형(latent growth curve modeling)을 사용하여 종단 연구를 실시하였는데 청소년의 반항성 행동 문제는 연령이 증감함에 따라 안정적이 거나 감소하는 경향을 나타냈다. 또한 Stepp, Burke, Hipwell과 Loeber (2012)의 연구에서는 8-14세 여자 아동 1,233명을 대상 으로 분할잠재성장모형(piecewise latent growth curve modeling) 을 이용하여 분석한 결과, 반항성 행동 장애는 8-10세 시기에 감소하는 경향을 나타냈지만 10-13세 시기에는 유의한 변화 가 없었다. 하지만 이러한 연구들은 아직까지 소수에 불과하 며 변수중심적 방법으로 잠재성장모형을 적용하여 유아 대상 의 반항성 행동 문제에 대한 발달 궤적을 살펴본 연구는 국내 외적으로 아직까지 존재하지 않는다.

반면에 개인들의 상이한 특성에 관심을 가지고 접근하는 대상중심적 접근 방식은 잠재계층성장모형(latent class growth model)을 이용하여 시간의 흐름에 따라 행동 발달에 있어서 특정 패턴을 보이는 상이한 잠재계층의 발달 궤적을 살펴볼 수 있는 방법이다. 잠재계층모형분석과 관련하여 반항성 행 동 문제에 관한 연구들은 영유아를 포함하여 아동 및 청소년 을 대상으로 하여 이미 여러 편(Ezpeleta et al., 2014; Tremblay, Duchesne, Vitaro, \& Tremblay, 2013)이 진행되었다. 이러한 대 상중심적 접근 방식은 변수중심적 접근 방식과 반대가 아닌 상호보완적이라고 볼 수 있는데 각각의 접근 방식의 사용은 연구 목적에 따라 달라질 수 있다(Chung, 2000). 종합해 볼 때 본 연구에서는 양적 연구의 포화상태일 때 진행하는 대상중 
심적 접근 방식 보다는 기초 현황자료가 부족한 상태에서 포 괄적으로 전체 표본에 적용되는 위험 요인이나 영향을 미치는 요인을 식별하는 변수중심적 접근 방식으로 유아의 반항성 행 동 문제의 발달 궤적을 살펴보는 것이 필요할 것이라 생각된 다.

한편, 부모 요인(Eiden, Edwards, \& Leonard, 2007; Pfiffner, McBurnett, \& Rathouz, 2005), 아동 요인(Speltz, McClellan, DeKlyen, \& Jones, 1999), 가족 요인(Qi \& Kaiser, 2003; Tremblay et al., 2013) 등 유아의 반항성 행동 문제의 위험 요 인에 관한 연구들은 횡단 연구나 종단 연구를 통해 이미 여러 편 수행되었다. 하지만 상대적으로 반대의 영향 관계 즉, 반 항성 행동 문제가 아동, 부모, 가족에게 미치는 영향을 살펴 본 연구는 미흡하며, 특히 반항성 행동 문제의 발달 궤적이 독 립변수로서 미치는 영향을 살펴본 연구는 거의 없다. 이와 관 련하여 기존 선행연구(Broidy et al., 2003; Burke, Waldman \& Lahey, 2010)에서 반항성 행동 문제는 수행 기능 결핍, 또래와 성인 간의 갈등, 우울, 자살생각, 학업 실패, 직업적 부적응, 비 행 등 여러 측면에서 부정적 영향을 미칠 수 있다고 보고하고 있다. 특히 반항성 행동 문제는 부모 변수 중에서 대표적으로 부모의 증가된 스트레스와 연관된다(Lee et al., 2010; Miranda, Marco, \& Grau, 2007; Pelham et al., 1997). 예를 들면, Goldstein, Harvey와 Friedman Weieneth (2007)의 연구에서는 3세 시기의 유아 258명의 부모를 조사한 결과, 과잉행동/반항 행동 문제 를 가진 유아들의 엄마가 이러한 문제가 없는 유아들의 엄마 와 비교했을 때 더 많은 스트레스가 있는 것으로 나타났다. 하 지만 이러한 연구들은 주로 $\mathrm{ADHD}$ 와 반항성 행동 문제가 함 께 공존한 상황에서 살펴보았기에 반항성 행동 문제가 부모의 양육스트레스에 미치는 영향을 명확히 파악하기 어렵고, 특히 대부분의 연구가 횡단 연구로 제한되어 있다.

부모의 양육스트레스와 같은 부모 변수 외에도 반항성 행 동 문제는 아동 변수와도 연관이 있는데 그중에서도 유아교 육기관이나 학교 등의 환경에 성공적인 적응에 매우 중요한 역할을 하는 자아통제에 영향을 미친다(American Psychiatric Association, 2013; DeGangi, 2017; Schoorl, van Rijn, de Wied, Van Goozen, \& Swaab, 2016). 자아통제는 정서나 행동을 조절 하는 능력을 의미하는 것으로 개인이 대응을 하기 전에 자동 적인 반응을 억제하고, 과거의 행동을 평가하게 하는 것을 가 능하게 하는데, 반항성 행동 문제를 가진 아동은 또래나 성인 과 적절하게 상호작용하거나 학교 관련된 과업을 완료하는 데 요구되는 자아통제력이 부족하다고 볼 수 있다(Reid, Trout, \& Schartz, 2005). 하지만 기존 선행 연구들(Barkley, 1997;
Seymour et al., 2012; Unnever, \& Cornell, 2003)은 반항성 행동 문제가 출현할 가능성이 매우 높다고 보고되고 있는 $\mathrm{ADHD}$ 와 자아통제 간의 관계를 횡단적으로 주로 살펴보았을 뿐 반 항성 행동 문제와 자아통제 간의 직접적인 경로를 살펴보지는 못하였다. 이러한 현황은 반항성 행동 문제가 자아통제력에 어떠한 영향을 미치는지를 살펴보는 것이 필요하다는 것을 보 여준다. 특히 시간의 흐름에 따라 변화되는 반항성 행동 문제 와 자아통제 간의 관계를 살펴보는 것은 그 인과관계의 방향 을 보다 명확히 파악하는데 도움이 될 것이다.

종합해 볼 때, 외국에서는 반항성 행동 문제의 원인에 초점 을 맞춘 연구들은 이미 많이 수행되고 있지만 반항성 행동 문 제가 부모의 양육스트레스나 유아의 자아통제 등에 미치는 결과에 초점을 맞추는 연구는 부족한 실정이다. 또한 대부분 의 연구들이 반항성 행동문제 보다는 DSM에 근거하여 장애 로 진단을 내리고 있는 반항성 행동 장애를 중심으로 연구하 고 있다. 국내 연구에서 역시 반항성 행동 문제에 관한 연구는 소수인데 그중에서도 지금까지 주로 영유아 및 아동을 중심으 로 반항성 장애의 치료에 관한 연구들(Chung \& Lee, 2003; S. Y. $\mathrm{Kim}, 2017)$ 이 대부분이다. 반항성 행동 문제에 영향을 미치는 원인에 관한 연구(H. Kim \& Lee, 2014)는 한편에 불과하고, 반 항성 행동 문제가 발달 산물에 어떠한 영향을 미치는지에 관 한 연구는 아직까지 진행된 바가 없다. 이러한 맥락에서 만일 종단연구를 통해 유아의 반항성 행동 문제가 부모의 양육스트 레스나 자아통제에 어떠한 영향을 미치는지 파악할 수 있다면 반항성 행동 문제의 조기 개입에 대한 중요성을 파악 할 수 있 는 근거자료를 마련하는 계기가 될 것이라 판단된다.

따라서 본 연구에서는 한국아동패널 5-7차년도의 자료를 사용하여 만 4세에서 6세까지 유아의 반항성 행동 문제 발달 궤적이 어떠한 양상으로 변화하는지 살펴보고, 이러한 발달궤 적이 부모의 양육스트레스와 유아의 자아통제에 미치는 영향 을 살펴보고자 한다. 본 연구는 반항성 행동 문제의 조기 개입 을 위한 유용한 기초 자료로 활용될 수 있을 것이라 기대한다.

본 연구의 연구문제는 다음과 같다.

\section{연구문제 1.}

유아의 반항성 행동 문제의 발달궤적은 어떠한가?

\section{연구문제 2.}

유아의 반항성 행동 문제의 발달궤적이 부모의 양육스트레스 와 유아의 자아통제에 어떠한 영향을 미치는가? 


\section{연구방법}

\section{연구대상}

본 연구는 전국적 대표성을 가진 종단 연구에 해당하는 한국 아동패널(The Panel Study on Korean Children [PSKC])을 사용 하였다. 한국아동패널은 육아지원 정책뿐만 아니라 아동, 부 모, 가족, 육아지원 서비스, 지역사회, 교사들의 특성에 관한 정보를 제공하기 위해 설계되었다. 한국아동패널은 전국의 의 료기관에서 2008년 4월부터 7월 사이에 출생한 2,078명의 가 구를 1차년도에 조사하여 10차년도(2017년)까지 데이터를 구 축하였고, 현재 8차년도까지 데이터를 공개하고 있다.

본 연구에서는 5차년도(2012년: 만 4세), 6차년도(2013년: 만 5세), 7차년도(2014년: 만 6세) 데이터를 사용하였는데 참 여율은 1 차년도에 대비할 때 5 차년도 $79.2 \%(1,703$ 가구), 6차 년도 77.3\%(1,662가구), 7차년도 75.3\%(1,602가구)로 나타났 다. 한편, 한국아동패널의 유아들은 2008년 4월에서 7월 사 이에 태어난 아기였기 때문에 2012년에는 만 4세, 2014년에 는 만 6 세가 되었다. 우리나라는 법적으로 만 3, 4, 5세를 매 년 1 월 1 일을 기준으로 하기 때문에 이들은 유치원이나 어린 이집에서 만 $3,4,5$ 세반을 다니고 있는 유아들이었다. 인구 학적 특성을 5 차년도를 기준으로 살펴보면 유아들의 나이는 만 4 세이었다. 남아의 비율이 $51.1 \%$ 이었고, 유아의 평균 월령 은 51.89 개월이었다. 또한 부모의 $81.2 \%$ 가 2년제 대학을 졸업 하였고, $99.1 \%$ 의 대부분 부모가 결혼한 상태이었다. 그리고 $4.3 \%$ 가 수급자나 차상위계층인 것으로 나타났다.

\section{연구도구}

본 연구에서는 반항성 행동 문제의 발달 궤적이 부모의 양육 스트레스와 유아의 자아통제에 미치는 영향을 살펴보기 위해 반항성 행동 문제는 5-7차년도(만 4-6세) 자료를 사용하였다. 부모의 양육스트레스와 유아의 자아통제는 모두 만 6세(7차 년도) 자료를 사용하였다.

\section{반항성 행동 문제}

본 연구의 독립 변수에 해당하는 유아의 반항성 행동 문제는 Achenbach와 Rescorla (2000)의 CBCL 1.5 5 (Child Behavior Checklist for ages 1.5-5)를 Y. A Kim, Lee, Moon, Kim and Oh (2009)가 국내 유아들에게 적합할 수 있도록 표준화한 유아
행동평가척도(Child Behavior Checklist 1.5 5)를 사용하여 측 정되었다. 이 척도는 여러 번의 예비 연구를 통해서 기본적인 신뢰도와 타당도를 검토하여 한국에서의 적용가능성이 확인 된 바 있다(Y. A. Kim, Oh, \& Lee, 2007). 유아행동평가척도는 DSM 진단 체계의 기준으로 평가해 볼 수 있는 5 가지 발달 문 제 척도를 얻을 수 있다. 이는 임상장면에서 심리 장애 진단체 계인 DSM과의 호환성을 고려하여 DSM 진단 기준에 맞춰 문 제 행동 문항을 분류한 척도로서 DSM 정서 문제, 불안 문제, 전반적 발달장애, $\mathrm{ADHD}$ 및 반항 행동 문제의 진단 점수가 해 당된다. 이중에서 반항성 행동 문제는 여러 문화권의 임상 전 문가들이 DSM 기준과 가장 일치하는 문항을 평정한 것으로 총 6문항(“반항적이다.”, "말을 안듣는다.”, "화가 나 보인다.”) 으로 구성된다. 각 문항은 3점 Likert 척도(전혀 해당되지 않는 다[0점], 가끔 그렇거나 그런 편이다[1점], 자주 그런 일이 있 거나 많이 그렇다[2점])로 부모나 보호자가 응답하도록 되어 있고, 점수가 높을수록 유아의 반항성 행동 문제 수준이 높다 는 것을 의미한다. 본 연구에서 반항성 행동 문제의 Cronbach's $\alpha=.73$ (만 4세), .72 (만 5세), .72 (만 6세)이었는데 반항성 행 동 문제는 왜도와 첨도가 정상분포에 가까운 $t$ 점수를 사용하 였다.

\section{부모의 양육스트레스}

본 연구의 종속변수에 해당하는 부모의 양육스트레스는 K H. Kim과 Kang (1997)이 개발한 양육스트레스 척도를 사용하 여 측정되었다. 이 문항은 "아이로부터 도망치고 싶을 때가 있 다.”, "양육 비용이 부담스럽다.”, “피곤할 때 아이가 놀아달라 고 보채면 귀찮은 생각이 든다” 등 총 11 문항으로 구성되어 있 고, 5점 Likert 척도(전혀 그렇지 않다[1], 매우 그렇다[5])로 부모가 응답하였다. 점수가 높을수록 부모의 양육스트레스 수 준이 높다는 것을 의미하고, 양육스트레스에 대한 Cronbach's $\alpha=.89$ (만 6세)이었다.

$$
\text { 유아의 자아통제 }
$$

본 연구의 종속변수에 해당하는 유아의 자아통제는 Gresham 과 Elliott (1990)의 도구를 Seo (2004)가 국내에서 타당화한 것 을 참고하여 한국아동패널 연구진이 수정 - 보완한 것을 사용 하여 측정되었다. 이 척도는 주장성, 협력성, 자아통제, 책임 성의 4 가지 하위요인으로 구성되었는데 이 중에서 유아의 자 아통제는 “다른 사람과 게임을 할 때 규칙을 지킨다.”, "부모의 
지시에 귀를 기울인다.” 등 총 7문항으로 이루어졌다. 각 문항 의 응답 방식은 3점 Likert 척도(전혀 아니다[1점], 매우 자주 그렇다[3점])로 부모가 응답하도록 되어 있다. 점수가 높을수 록 유아의 자아통제 수준이 높다는 것을 의미하고, 유아의 자 아통제에 대한 Cronbach's $\alpha=.80$ (만 6세)이었다.

\section{연구모형 및 분석방법}

본 연구에서 반항성 행동 문제의 발달 궤적이 부모의 양육스 트레스와 유아의 자아통제에 미치는 영향 관계에 대한 모형은 Figure 1과 같다.

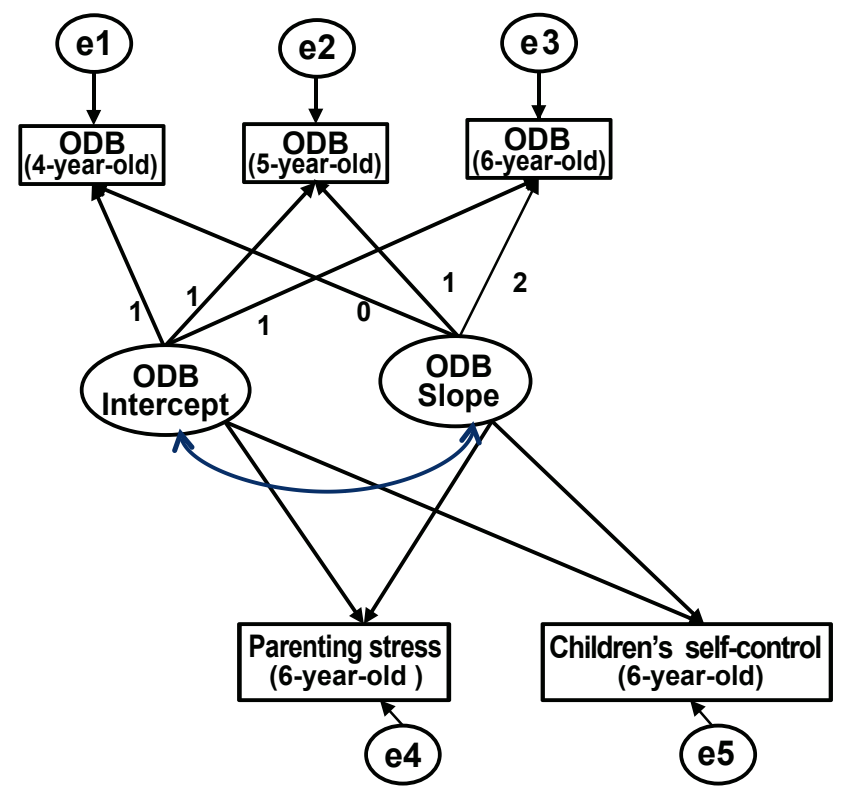

Figure 1. Research model

본 연구에서는 기술통계를 위해 SPSS 18.0, 잠재성장모형 분석을 위해 Amos 21.0을 각각 사용하였다. 분석 절차로 첫 째, 잠재성장모형(latent growth curve model)의 무조건모형 (unconditional model)을 사용하여 유아의 반항성 행동 문제의 발달 궤적을 살펴보았다. 둘째, 잠재성장모형의 조건모형을 활용하여 유아의 반항성 발달궤적이 부모의 양육스트레스와 유아의 자아통제에 어떤 영향을 미치는지 확인하였다. 결측 치 문제 해결을 위해서 완전정보최대우도법(Full Information Maximum Likelihood [FIML])을 사용하여 투입된 모든 변수 의 정보를 사용하여 결측치를 추정하였다. 모형 적합도는 $\chi^{2}$, RMSEA, TLI, CFI를 통해 확인하였는데 TLI, CFI는 .90이상, RMSEA는 .06미만이면 모형이 적합하고 수용가능하다고 판 단된다(Hu \& Bentler, 1999).

\section{결과 및 해석}

\section{주요 변수의 기술통계}

본 연구의 주요변수 기술통계는 Table 1 과 같다. 먼저, 본 연 구의 독립변수인 반항성 행동 문제는 만 4 세 시기의 평균이 53.53 점 $(S D=5.32)$, 만 5 세 시기의 평균이 52.59 점 $(S D=4.71)$, 만 6세 시기의 평균이 52.19점 $(S D=4.32)$ 으로 나타나 연령이 증가할수록 조금씩 줄어드는 것으로 나타났다. 또한 종속변수 인 만 6세 시기의 부모의 양육스트레스는 평균이 2.49점 $(S D=$ .52)으로 최대값이 4점임을 고려했을 때 중간 정도 수준이라 고 볼 수 있다. 만 6세 시기 유아의 자아통제는 최대값이 3점 임을 고려할 때 비교적 높은 편임을 알 수 있다. 잠재성장모형 분석을 위한 데이터의 정상성(normality) 검정은 모두 왜도가 절대값 3 이하, 첨도가 절대값 10 이하로 정규분포 가정을 만족 시켰다(Kline, 2010).

반항성 행동 문제와 부모의 양육스트레스, 유아의 자아통 제와의 상관관계를 살펴본 결과는 Table 2 와 같다. 만 4 세부터 만 6 세 시기까지 매 시기의 반항성 행동 문제는 서로 유의한

Table 1

Descriptive Statistics of Major Variables

\begin{tabular}{|c|c|c|c|c|c|c|}
\hline Variables & $M$ & $S D$ & Min. & Max. & Skewness & Kurtosis \\
\hline \multicolumn{7}{|l|}{ Independent variables } \\
\hline Oppositional defiant behavior (4-year-old) & 53.53 & 5.32 & 50 & 82 & 1.66 & 2.68 \\
\hline Oppositional defiant behavior (6-year-old) & 52.19 & 4.32 & 50 & 76 & 2.31 & 5.50 \\
\hline \multicolumn{7}{|l|}{ Dependent variables } \\
\hline
\end{tabular}


Table 2

Correlation of Major Variables

\begin{tabular}{|c|c|c|c|c|c|}
\hline & 1 & 2 & 3 & 4 & 5 \\
\hline 1. Oppositional defiant behavior (4-year-old) & - & & & & \\
\hline 2. Oppositional defiant behavior (5-year-old) & $.48^{* *}$ & - & & & \\
\hline 4. Parenting stress (6-year-old) & $.20^{* *}$ & $.25^{* *}$ & $.27^{* *}$ & - & \\
\hline 5. Children's self-control (6-year-old) & $-.26^{* *}$ & $-.25^{* *}$ & $-.32^{* *}$ & $-.27^{* *}$ & - \\
\hline
\end{tabular}

${ }^{* *} p<.01$.

정적인 상관관계가 있는 것으로 나타났다. 또한 만 4세부터 6 세 시기까지의 반항성 행동 문제는 모두 부모의 양육스트레스 와 정적인 상관관계가 있었지만 유아의 자아통제와는 부적인 상관관계가 있는 것으로 나타났다.

\section{반항성 행동 문제의 무조건모형}

무조건 모형은 측정 시점에 따른 반항성 행동 문제의 변화 양 상의 확인을 가능하게 한다. 이와 관련하여 본 연구에서는 유 아의 반항성 행동 문제의 발달궤적을 검증하기 위해 초기치와 변화율을 잠재변수로 하여 만 4-6세까지 이어지는 경로를 설 정하였다. 초기치는 잠재변수에서 각 측정변인으로 가는 경로 를 각각 1 로 고정하였고, 변화율은 $0,1,2$ 로 고정하여 선형 변 화 모형을 구축하였다. 반항성 행동 문제의 무조건 모형 분석 결과는 Figure 2, Table 3과 같다.

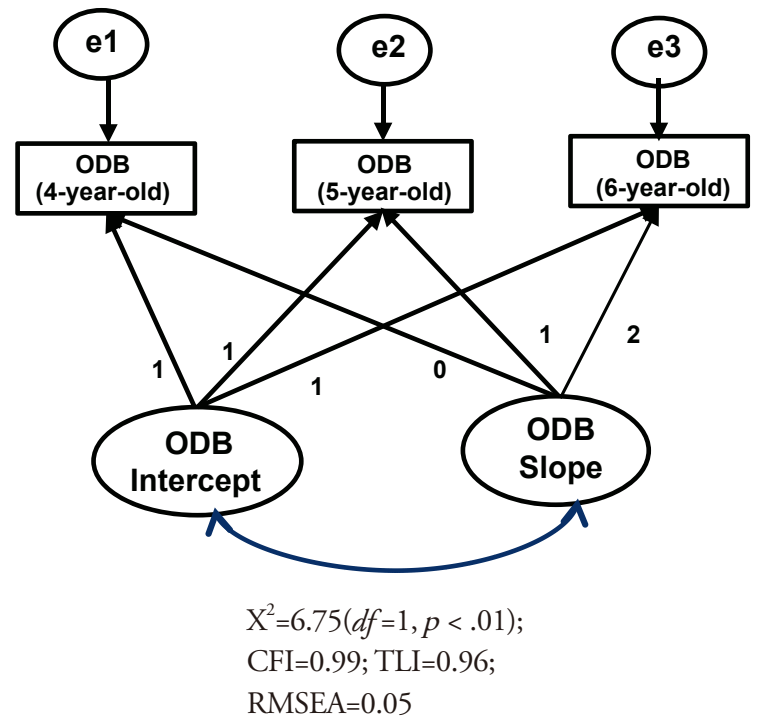

Figure 2. Results of unconditional research model.
반항성 행동 문제 무조건모형의 적합도를 보면, $\chi^{2}$ 이 통계 적으로 $p<.01$ 수준에서 유의하였지만, 절대적합지수가 $\mathrm{CFI}=$ $0.99, \mathrm{TLI}=0.96, \mathrm{RMSEA}=0.05$ 로 나타나 모형 적합도 지수에 서 매우 좋은 적합도를 보여주었다.

무조건 모형에서 추정된 성장모수치를 살펴보면, 반항성 행동 문제의 초기치 평균은 $53.41(p<.001)$ 로 이는 만 4 세 시 기의 반항성 행동 문제의 평균이 53.41 점이라는 것을 의미한 다. 또한 변화율의 평균은 -.66 ( $p<.001)$ 으로 연령이 높아질수 록 해마다 반항성 행동 문제가 -.66점씩 감소하는 것을 의미한 다. 그리고 반항성 행동 문제의 초기치와 변화율에 대한 변량 이 각각 $14.48,1.64$ 로 모두 $p<.001$ 수준에서 유의한 것으로 나타났는데 이는 유아의 초기치와 변화율 모두가 평균을 중심 으로 개인차가 충분해서 개인차를 예측하거나 개인차가 미치 는 영향을 살펴보기 위한 조건부 모형이 가능하다는 것을 의 미한다.

\section{반항성 행동 문제의 조건모형}

반항성 행동 문제의 발달궤적이 부모의 양육스트레스와 유아 의 자아통제에 미치는 영향을 살펴보기 위한 조건모형의 분석 결과는 Table 4, Figure 3과 같다. 반항성 행동 문제 조건모형의 적합도를 보면, $\chi^{2}$ 이 통계적으로 $p<.01$ 수준에서 유의하였지 만, 다른 모형적합도가 $\mathrm{CFI}=0.99, \mathrm{TLI}=0.96, \mathrm{RMSEA}=0.05$ 로 나타나 조건모형이 수용 가능하다고 볼 수 있다.

조건모형의 분석 결과를 살펴보면, 반항성 행동 문제의 초 기치와 변화율은 만 6 세 시기의 부모의 양육스트레스에 정적 영향을 미치는 것으로 나타났다. 이는 만 4세 시기 유아의 반 항성 행동 문제 초기치가 높을수록( $\beta=.70, p<.001)$ 만 6 세 시기의 부모의 양육스트레스 수준이 높았고, 조사기간 3 년 동 안 반항성 행동 문제 수준의 감소 속도가 느릴수록 $(\beta=.59, p$ <.01) 부모의 양육스트레스가 증가했다는 것을 의미한다. 
Table 3

Results of Unconditional Model

\begin{tabular}{|c|c|c|c|c|}
\hline & \multicolumn{2}{|c|}{ Intercept } & \multicolumn{2}{|c|}{ Slope } \\
\hline & $M$ & Variance & $M$ & Variance \\
\hline Oppositional defiant behavior & $53.41^{* * *}$ & $14.48^{* * *}$ & $-.66^{* * *}$ & $1.64^{* * *}$ \\
\hline
\end{tabular}

${ }^{* *} p<.01 .{ }^{* * *} p<.001$.

Table 4

Results of the Conditional Model

\begin{tabular}{lllll}
\hline \multicolumn{1}{c}{ Paths } & B & $\beta$ & $S E$ & C.R. \\
\hline ODB Intercept $\rightarrow$ Parenting stress (6-year-old) & .10 & .70 & .02 & $5.632^{* * *}$ \\
ODB Slope $\rightarrow$ Parenting stress (6-year-old) & .47 & .59 & .16 & $3.005^{* *}$ \\
ODB Intercept $\rightarrow$ Children's self-control (6-year-old) & -.07 & -.72 & .01 & $-6.995^{* * *}$ \\
ODB Slope $\rightarrow$ Children's self-control (6-year-old) & -.29 & -.53 & .08 & $-3.468^{* * *}$
\end{tabular}

${ }^{* *} p<.01 .{ }^{* * *} p<.001$.

반항성 행동 문제의 초기치와 변화율은 만 6세 시기의 유 아의 자아통제에 부적 영향을 미치는 것으로 나타났다. 이는 만 4세 시기 유아의 반항성 행동 문제 초기치가 높을수록 $(\beta=$ $-.72, p<.001)$ 만 6 세 시기의 유아의 자아통제 수준이 낮았고, 조사기간 3 년 동안 반항성 행동 문제 수준의 감소 속도가 빠 를수록 $(\beta=-.53, p<.001)$ 유아의 자아통제 수준이 증가했다는 것을 의미한다.

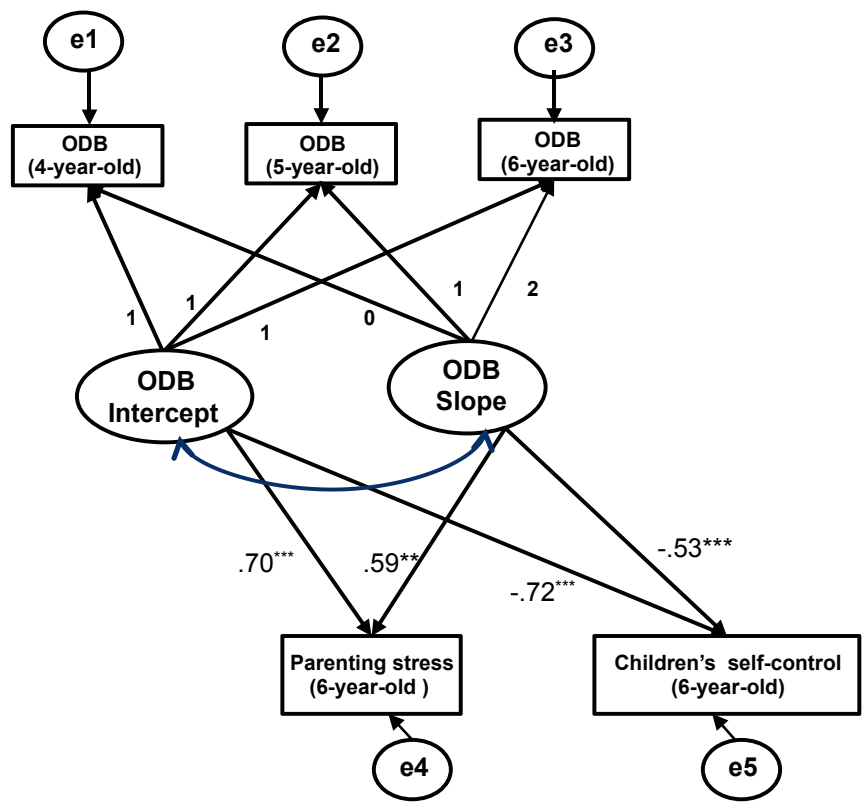

Figure 3. Results of conditional model. $\mathrm{X}^{2}=22.18(d f=4, p<.001)$; $\mathrm{CFI}=0.99 ; \mathrm{TLI}=0.95 ; \mathrm{RMSEA}=0.05$

${ }^{* *} p<.01 .{ }^{* * *} p<.001$.

\section{논의 및 결론}

본 연구는 한국아동패널을 사용하여 유아의 반항성 행동 문제 의 발달궤적이 부모의 양육스트레스와 유아의 자아통제에 어 떠한 영향을 미치는지 살펴보고자 하였다.

본 연구의 연구결과 및 논의는 다음과 같다.

첫째, 만 4세 시기의 유아의 반항성 행동 문제는 유아 개개인 마다 차이가 있고, 유아의 연령이 증가함에 따라 반항성 행동 문제의 변화율에도 개인차가 있으며 전반적으로 계속 감소하 는 추세를 보였다. 이러한 결과는 본 연구와 연령대는 다르지만 12-18세 청소년의 반항성 행동 문제가 연령이 증가하면서 안정 적이거나 감소하는 경향이 나타난 Leadbeater 등(2012)의 연구 결과와 유사한 것으로 나타났다. 또한 반항성 행동 장애는 8-10 세 시기에 감소하였지만 10-13세 시기에는 안정적인 것으로 나 타난 Step 등(2012)의 연구결과와도 비슷한 경향을 나타냈다. 하지만 Ezpeleta 등(2014)의 연구에서 잠재계층모형 분석을 한 결과, 3-5세 유아 622 명의 반항성 행동 문제 발달 궤적이 지속적 으로 낮은 그룹 78\%, 높았다가 낮아진 그룹 $9.4 \%$, 낮았다가 높 아진 그룹 $9.4 \%$ 로 나타나 본 연구결과와는 다소 차이가 있었 다. 또한 29 개월에서 74 개월까지의 반항성 행동 문제 발달 궤적 을 분석한 Petitclerc 등(2009)의 연구에서는 시간이 지나도 매우 낮은 그룹 9\%, 낮은 그룹 $56.9 \%$, 보통 그룹 $29.7 \%$, 만성적으로 높은 그룹 4.3\%로 그대로 유지되는 것으로 나타났다. 이는 본 연구에서 잠재성장모형 분석을 시도한 것과 달리 잠재계층성 장분석을 시도한 것에서 기인한 차이라고 여겨지며, 향후 본 연 구의 자료를 사용하여 대상 중심적 접근의 잠재계층성장분석 
을 실시한 후 어떠한 계층으로 구분되는지 살펴보고 이를 통해 비교하는 것이 필요하리라 판단된다.

둘째, 만 4세 시기 유아의 반항성 행동 문제의 초기치는 만 6세 시기의 부모의 양육스트레스에 유의한 정적 영향을 미쳤 고, 만 6세 시기의 유아의 자아통제에 부적 영향을 미치는 것 으로 나타났다. 이는 만 4 세 시기의 유아의 반항성 행동 문제 가 증가할수록 만 6 세 시기의 부모의 양육스트레스 수준이 증 가하고, 유아의 자아통제가 낮아진다는 것을 의미한다. 3 년 이라는 긴 시간 간격에도 이러한 영향관계가 나타난다는 것 은 반항성 행동 문제의 영향력이 매우 강력하다는 것을 시 사한다. 이러한 결과는 기존 선행 연구결과(Lee et al., 2010; Miranda et al., 2007; Pelham et al., 1997)와 유사하게 나타났다. 구체적인 예로, 3 세 유아 258 명의 어머니를 조사 했을 때 과 잉행동/반항 행동 문제를 가진 유아들의 어머니가 그렇지 않 은 유아의 어머니에 비해 더 많은 스트레스가 있는 것으로 나 타난 Goldstein 등(2007)의 연구결과와 유사하였다. 또한 반항 성 행동 문제를 가진 아동은 또래나 성인과의 관계에서 적절 하게 상호작용하거나 학업 수행하는데 있어서 필요한 자아 통제력이 부족하다고 한 Reid 등(2005)의 주장과도 유사하였 다. 하지만 이러한 주장을 하고 있는 선행연구들(Barkley, 1997; Seymour et al., 2012; Unnever, \& Cornell, 2003)이 대부분 반항 성 행동 문제가 함께 동반될 가능성이 높은 $\mathrm{ADHD}$ 와 자아통 제 간의 관계를 살펴보았기 때문에 본 연구결과와 직접 비교 하기에는 어려움이 있다. 따라서 반항성 행동 문제가 유아의 자아통제에 어떠한 영향을 미치는지 직접적으로 살펴본 후속 연구결과와의 비교를 통해 보다 명확한 인과관계를 살펴보는 것이 필요할 것이라 사료된다.

한편, 본 연구에서 조사 기간 3년 동안 반항성 행동 문제의 변화율은 부모의 양육스트레스에 정적 영향을 미쳤고, 유아의 자아통제에 부적 영향을 미쳤다. 이는 조사기간 3년 동안 반항 성 행동 문제 수준의 감소 속도가 느릴수록 부모의 양육스트레 스가 증가하고, 반항성 행동 문제 수준의 감소 속도가 빠를수 록 유아의 자아통제 수준이 증가했다는 것을 의미한다. 이러한 결과는 앞서 제시한 만 4 세 시기의 유아의 반항성 행동 문제의 초기치가 높을수록 6세 시기의 부모의 양육스트레스 수준이 높고, 유아의 자아통제 수준이 낮다는 것과 유사한 결과이다. 하지만 초기치와 달리 변화율이 영향을 미친다는 것은 조사기 간 동안 종단적으로 영향을 미치는 것을 의미하는 것으로 반항 성 행동 문제의 영향력을 더 분명하게 보여준 것이라고 할 수 있다. 따라서 유아기 시기에 반항성 행동 문제가 나타나 부모 가 스트레스를 받거나 유아가 자아통제 수준이 떨어지는 것으
로 인식되면 반항성 행동 문제 수준이 빠르게 감소할 수 있도 록 효과적인 방법으로 개입을 해 주는 것이 부모나 유아 자신 에게 있어 장기적인 측면에서 중요하다는 것을 시사해 준다.

본 연구의 함의는 다음과 같다.

첫째, 반항성 행동 문제의 조기 진단은 무엇보다 중요하 다. 즉, 반항성 행동 문제가 정상적인 발달과정인지 행동 문제 인지를 신중히 판단해야 한다. 본 연구에서 반항성 행동 문제 는 초기치나 변화율 모두가 부모의 양육스트레스와 유아의 자아통제에 유의한 영향을 미치는 것으로 나타나 반항성 행 동 문제의 발현 시 조기 개입이 중요하다고 볼 수 있다. 그러 나 주의해야 할 점은 American Academy of Child and Adolescent Psychiatry (2011)가 언급한 바와 같이 모든 아동들은 때때로 피 곤하고, 배고프고, 스트레스를 받거나 화가 날 때 반항을 하는 데 이러한 반항적 행동은 2-3세 아동이나 초기 청소년기에 나 타나는 정상적인 발달 과정 중 한 부분일 수 있다. 따라서 유아 와 가장 많은 시간을 보내는 부모와 교사는 유아가 반항적인 행동을 보였을 때 이것이 일시적으로 나타나는지 아니면 지속 적으로 나타나는지를 주의 깊게 살펴보아야 한다. 이러한 과 정을 통해서 유아의 반항적인 행동이 단순히 기본적인 욕구 의 불만족이나 스트레스로 인한 것이라면 유아가 필요로 하는 기본적인 욕구들을 충족시켜주거나 스트레스가 되는 원인들 을 제거해 주는 것이 필요하다. 하지만 이러한 노력에도 불구 하고 반항적 행동이 사라지지 않고 계속된다면 반항적 행동의 정도가 커지고 있는지 아니면 감소하고 있는지의 변화 정도를 살피면서 최소 6 개월 이상 지속되었을 때에 전문가에게 전문 적인 검사 및 치료를 의뢰해야 한다.

둘째, 반항성 행동 문제 유아에 대한 조기 개입과 더불어 치 료가 필요하다. 만 4세 시기의 유아의 반항성 행동 문제는 유 아마다 개인차가 있고, 유아의 연령이 증가함에 따라 반항성 행동 문제는 개인차가 존재하지만 전반적으로 계속 감소하는 경향이 있는 것으로 나타났다. 이러한 결과에 비추어 볼 때 연 령이 증가할수록 반항성 행동 문제가 감소하지 않거나 감소 하더라도 느리게 감소하는 유아들이 있다면 규칙적인 일대일 관계, 긍정적인 행동에 관한 역할놀이(role play), 효과적인 칭 찬 등 일상생활에서 사용할 수 있는 방법을 통한 개입이 필요 하다(Yates, 2017). 이러한 개입을 했음에도 불구하고 유아의 반항적 문제 행동이 계속되면서 부모나 교사를 힘들게 한다 면 기존 선행연구(Cho \& Kong, 2003; S. Y. Kim, 2017)에서 효 과성이 검증된 놀이치료나 미술치료 등 전문적인 심리 치료를 통해 행동의 변화가 일어나도록 해야 할 것이다.

셋째, 반항성 행동 문제를 보이는 유아의 부모에 대한 개 
입과 더불어 유아의 자아통제력을 높일 수 있는 방안 마련이 필요하다. 본 연구 결과 만 4 세 시기 유아의 반항성 행동 문제 의 초기치와 변화율은 만 6 세 시기의 부모의 양육스트레스나 유아의 자아통제에 부정적인 영향을 미치는 것으로 나타났 다. 이러한 결과에서 반항적 행동 문제를 보이는 유아의 부모 경우에는 양육스트레스 감소를 위한 개입이 필요하다. 이와 관련하여 기존 선행 연구(Costin, Lichte, Hill-Smith, Vance, \& Luk, 2004; Doo \& Lee, 2012)에서는 부모의 스트레스 감소를 위한 집단 프로그램 적용이 효과적이며 이러한 부모의 개입을 통해서 유아들의 반항성 행동 문제도 감소하는 것으로 밝혀졌 다. 이를 적용하여 유아교육기관에서는 정기적으로 반항성 행 동 문제 등 문제행동을 보이는 유아 부모들을 대상으로 소그 룹 부모교육을 진행할 수 있다. 부모교육 시간에는 원장과 교 사가 함께 하여 부모 역할을 하면서 경험하는 어려움을 이야 기 나누고, 서로 격려와 지지를 받는 시간이 되도록 해야 한다.

또한 반항성 행동 문제를 보이는 유아의 자아통제 능력을 향상시키기 위해서는 부모나 교사의 역할이 가장 중요하다고 볼 수 있는데 유아가 자신의 행동을 통제할 수 있도록 직접적으 로 지도해 주거나 모방학습이 가능하도록 모델링을 제공하는 것이 필요하다(S. H. Kim, 2014). 또한 $\mathrm{Ha}$ (2016)가 제안하였듯 이 자기 점검, 자기 평가, 자기 강화를 통해 자신의 행동을 관리 하도록 가르치는 자기 관리 훈련이나 자신의 행동을 조절할 수 있도록 다양한 상황에서 자신에게 내적으로 말하기(혼잣말)를 연습하는 자기 지시 방법을 가르쳐 주는 등 유아의 상황에 따라 다양한 전략을 시도하는 것이 필요할 것이라 여겨진다.

본 연구는 종단 연구로서 유아의 반항성 행동 문제가 시간 의 흐름에 따라 어떻게 변화하는지 살펴보고, 그 문제가 부모 의 양육스트레스나 유아의 자아통제에 어떠한 영향을 미치는 지 살펴보았다는데 의의가 있지만, 후속 연구를 위한 제안을 하면 다음과 같다. 먼저 본 연구에서 반항성 행동 문제는 DSM 진단 체계의 기준으로 5가지 발달 문제 수준을 평가할 수 있는 유아행동평가 척도의 5 문항으로 측정하였기에 반항성 행동 장애 진단을 받은 유아의 결과와는 차이가 있을 수 있다. 따라 서 후속 연구에서는 임상에서 반항성 행동 장애 진단을 받은 유아만을 대상으로 하여 분석한 후 본 연구의 반항성 행동 문 제를 보이는 유아의 결과와 비교해 보는 것이 필요할 것이라 여겨진다. 또한 본 연구에서는 개인의 특성에 관심을 가지고 접근하는 대상중심적 접근 방식인 잠재계층성장 모형 분석이 아닌 연령 증가에 따른 반항성 행동 문제의 평균적인 변화율 을 살펴봄으로써 일반적인 변화 양상을 확인할 수 있었다. 따 라서 후속 연구에서는 연령이 증가함에 따라 반항성 행동 문
제가 상이한 잠재계층으로 구분되는지, 잠재계층에 따라 어떻 게 상이하게 변화하는지를 살펴볼 수 있는 잠재계층성장 모형 분석을 시도하여 본 연구의 결과를 보완하여 주는 것이 필요 할 것이라 생각된다.

\section{Acknowledgement}

This work was supported by the National Research Foundation of Korea Grant funded by the Korean Government (NRF2016S1A3A2924375).

\section{Notes}

This article was presented orally at the 2017 Annual Fall Conference of the Korean Association of Child Studies.

\section{Conflict of Interest}

No potential conflict of interest relevant to this article was reported.

\section{References}

\section{In English}

Achenbach, T. M., \& Rescorla, L. A. (2000). Manual for the ASEBA preschool forms and profiles. Burlington, VT: Research Center for Children, Youth, \& Families.

American Academy of Child and Adolescent Psychiatry. (2011). Children with oppositional defiant disorder. Facts for families. Retrieved June 10, 2017, from http://www.aacap.org/

American Psychiatric Association. (2013). Diagnostic and statistical manual of mental disorders (5th ed.). Arlington, VA: American Psychiatric Publishing.

Barkley, R. A. (1997). ADHD and the nature of self-control. New York: Guilford Press.

Broidy, L. M., Tremblay, R. E., Brame, B., Fergusson, D., Horwood, J. L., Laird, R., . . V Vitaro, F. (2003). Developmental trajectories of childhood disruptive behaviors and adolescent delinquency: A six-site, crossnational study. Developmental Psychology, 39(2), 222-245. 
doi:10.1037/0012-1649.39.2.222

Burke, J. D., Waldman, I., \& Lahey, B. B. (2010). Predictive validity of childhood oppositional defiant disorder and conduct disorder: Implications for the DSM-V. Journal of Abnormal Psychology, 119(4), 739-751. doi:10.1037/a0019708

Chung, I.-J. (2000). Developmental trajectories of offending among poor and non-poor children (Doctoral dissertation). Retrieved from http://www.riss.kr/link?id=T8447557

Costin, J., Lichte, C., Hill-Smith, A., Vance, A., \& Luk, E. (2004). Parent group treatments for children with oppositional defiant disorder. Australian e-Journal for the Advancement of Mental Health, 3(1), 36-43. doi:10.5172/jamh.3.1.36

DeGangi, G. A. (2017) Problems of self-regulation in children: A longitudinal case study of a child from infancy to adulthood. Journal of Psychology and Clinical Psychiatry, 7(2), 00428(112). doi:10.15406/jpcpy.2017.07.00428

Eiden, R. D., Edwards, E. P., \& Leonard, K. E. (2007). A conceptual model for the development of externalizing behavior problems among kindergarten children of alcoholic families: Role of parenting and children's self-regulation. Developmental Psychology, 43(5), 1187-1201. doi:10.1037/0012-1649.43. 5.1187

Ezpeleta, L., Granero, R., de la Osa, N., Navarro, J. B., Penelo, E., \& Domènech, J. M. (2014). Tracing developmental trajectories of oppositional defiant behaviors in preschool children. PLoS ONE, 9(6), e101089. doi:10.1371/journal. pone. 0101089

Goldstein, L. H., Harvey, E. A., \& Friedman-Weieneth, J. L. (2007). Examining subtypes of behavior problems among 3-year-old children, Part III: Investigating differences in parenting practices and parenting stress. Journal of Abnormal Child Psychology, 35(1), 125-136. doi:10.1007/ s10802-006-9047-6

Gresham, F. M., \& Elliot, S. N. (1990). Social skills rating system: Manual. Circle Pines, MN: American Guidance Service.

Harvey, E. A., Friedman-Weieneth, J. L., Goldstein, L. H., \& Sherman, A. H. (2007). Examining subtypes of behavior problems among 3-year-old children, Part I: Investigating validity of subtypes and biological risk-factors. Journal of Abnormal Child Psychology, 35(1), 97-110. doi:10.1007/ s10802-006-9087-y

Hu, L., \& Bentler, P. M. (1999). Cutoff criteria for fit indexes in covariance structure analysis: Conventional criteria versus new alternatives. Structural Equation Modeling: A Multidisciplinary Journal, 6(1), 1-55. doi:10.1080/10705519909540118

Kline, R. B. (2010). Principles and practice of structural equation modeling: Methodology in the Social Sciences (3rd ed.). New York: Guilford Publications.

Kofler, M. J., Larsen, R., Sarver, D. E., \& Tolan, P. H. (2015). Developmental trajectories of aggression, prosocial behavior, and social-cognitive problem solving in emerging adolescents with clinically elevated attention-deficit/hyperactivity disorder symptoms. Journal of Abnormal Psychology, 124(4), 1027-1042. doi:10.1037/abn0000103

Leadbeater, B., Thompson, K., \& Gruppuso, V. (2012). Cooccurring trajectories of symptoms of anxiety, depression, and oppositional defiance from adolescence to young adulthood. Journal of Clinical Child and Adolescent Psychology, 41(6). 719-730. doi:10.1080/15374416.2012.694608

Lee, P., Lee, T., Chen, V. C., Chen, M., Shih, D., Shao, W., Shao, W., Lee, M-C. (2010). Quality of life in mothers of children with oppositional defiant symptoms: A community sample. Mental Health in Family Medicine, 7(2), 93-100.

Leve, L. D., Kim, H. K., \& Pears, K. C. (2005). Childhood temperament and family environment as predictors of internalizing and externalizing trajectories from ages 5 to 17. Journal of Abnormal Child Psychology, 33(5), 505-520. doi:10.1007/s10802-005-6734-7

Loeber, R., Burke, J. D., Lahey, B. B., Winters, A., \& Zera, M. (2000). Oppositional defiant and conduct disorder: A review of the past 10 years, Part I. Journal of the American Academy of Child and Adolescent Psychiatry, 39(12), 14681484. doi:10.1097/00004583-200012000-00007

Miranda, A., Marco, R., \& Grau, D. (2007). Parenting stress in families of children with attention-deficit/hyperactivity disorder: The impact of ADHD subtype and oppositional defiant disorder comorbidity In T. E. Scruggs, M. A. Mastropieri (Ed.), Advances in Learning and Behavioral Disabilities: International perspectives (Vol. 20, pp. 139162). Bingley, WY: Emerald Group Publishing Limited.

Nagin, D., \& Tremblay, R. E. (1999). Trajectories of boys' physical aggression, opposition, and hyperactivity on the path to physically violent and nonviolent juvenile delinquency. Child Development, 70(5), 1181-1196. doi:10.1111/14678624.00086

Pelham, W. E., Lang, A. R., Atkeson, B., Murphy, D. A., Gnagy, E. M., Greiner, A. R., . . . Greenslade, K. E. (1997). Effects of deviant child behavior on parental distress and alcohol consumption in laboratory interactions. Journal of Abnormal Child Psychology, 25(5), 413-424. doi:10.1023/ A: 1025789108958

Petitclerc, A., Boivin, M., Dionne, G., Zoccolillo, M., \& Tremblay, R. E. (2009). Disregard for rules: The early development and predictors of a specific dimension of disruptive behavior disorders. Journal of Child Psychology and Psychiatry, 50(12), 1477-1484. doi:10.1111/j.1469-7610.2009.02118.x

Pfiffner, L. J., McBurnett, K., Rathouz, P. J., \& Judice, S. (2005). Family correlates of oppositional and conduct disorders in children with attention deficit/hyperactivity disorder. Journal of Abnormal Child Psychology, 33(5), 551-563. 
doi:10.1007/s10802-005-6737-4

Qi, C. H., \& Kaiser, A. P. (2003). Behavior problems of preschool children from low-income families: Review of the literature. Topics in Early Childhood Special Education, 23(4), 188-216.

Reid, R., Trout, A. L., \& Schartz, M. (2005). Self-regulation interventions for children with attention deficit/hyperactivity disorder. Exceptional Children, 71(4), 361-377.

Romeo, R., Knapp, M., \& Scott, S. (2006). Economic cost of severe antisocial behaviour in children-and who pays it. The British Journal of Psychiatry, 188(6), 547-553. doi:10.1192/ bjp.bp.104.007625

Schoorl, J., van Rijn, S., de Wied, M., van Goozen, S., \& Swaab, H. (2016). Emotion regulation difficulties in boys with oppositional defiant disorder/conduct disorder and the relation with comorbid autism traits and attention deficit traits. PLoS ONE, 11(7), e0159323. doi:10.1371/journal.pone.0159323

Seymour, K. E., Chronis-Tuscano, A., Halldorsdottir, T., Stupica, B., Owens, K., \& Sacks, T. (2012). Emotion regulation mediates the relationship between ADHD and depressive symptoms in youth. Journal of Abnormal Child Psychology, 40(4), 595-606. doi:10.1007/s10802-013-9799-8

Speltz, M. L., McClellan, J., DeKlyen, M., \& Jones, K. (1999). Preschool boys with oppositional defiant disorder: Clinical presentation and diagnostic change. Journal of the American Academy of Child and Adolescent Psychiatry, 38(7), 838-845. doi:10.1097/00004583-199907000-00013

Stepp, S. D., Burke, J. D., Hipwell, A. E., \& Loeber, R. (2012). Trajectories of attention deficit hyperactivity disorder and oppositional defiant disorder symptoms as precursors of borderline personality disorder symptoms in adolescent girls. Journal of Abnormal Child Psychology, 40(1), 7-20. doi:10.1007/s10802-011-9530-6

Tremblay, M., Duchesne, S., Vitaro, F., \& Tremblay, R. E. (2013). Developmental trajectories of oppositional behavior during elementary school and their risk factors. Journal of Educational and Developmental Psychology, 3(1), 234-243. doi:10.5539/jedp.v3n1p234

Unnever, J. D., \& Cornell, D. G. (2003). Bullying, self-control, and ADHD. Journal of Interpersonal Violence, 18(2), 129-147.

Yates, E. (2017). Oppositional defiant disorder parenting and preventing behavior problems. Smarter Parenting. Retrieved February 6, 2018, from http://www.smarterparenting.com/

\section{In Korean}

Cho, Y.-S., \& Kong, M. (2003). Case study for the aggression of children with oppositional disorder. Korean Journal of Art Therapy, 10(2), 321-344.

Chung, K-S., \& Lee, E-H. (2003). A case study on child-centered play therapy for a young child with oppositional/defiant behavior problems. Journal of Early Childhood Education, $12,51-78$

Doo, J.-I, \& Lee, J.-S. (2012). The effectiveness of group parentchild interaction therapy for children with disruptive behavioral problems and their mothers. The Korean Journal of Counseling and Psychotherapy, 24(2), 339-363.

Ha, E. H. (2016). Adongbokjisiseol ipso adongui munjehaengdong yuhyeonge ttareun saenghwaljido maenyueol[아동복지시 설 입소 아동의 문제 행동 유형에 따른 생활 지도 매뉴 얼]. Seoul: Ministry of Health and Welfare.Korea National Association of Child Welfare.

Kim, H., \& Lee, S. (2014). The effects of infants'temperament and mothers' child-rearing attitudes on infants' problem behaviors in child care centers. Journal of Korean Council for Children and Rights, 18(1), 123-146.

Kim, K. H., \& Kang, H. K. (1997). Development of the parenting stress scale. Family and Environment Research, 35(5), 141-150.

Kim, S.-H. (2014). The moderating effects of the teacher-child relationship on the relationship between young children's self-control and behavior problems. Korean Journal of Child Studies, 35(3), 31-47. doi:10.5723/KJCS.2014.35.3.31

Kim, S. Y. (2017). A case study on child-centered play therapy for a child with ADHD and ODD: Focusing on the change of play theme at stage. Korean Journal of Child Studies, 38(4), 103-115. doi:10.5723/kjcs.2017.38.4.103

Kim, Y. A., Lee, J., Moon, S.-J., Kim, Y.-J., \& Oh, K. J. (2009). Standardization study for the Korean version of the child behavior checklist for ages 1.5-5. The Korean Journal of Clinical Psychology, 28(1), 117-136.

Kim, Y. A., Oh, K. J., \& Lee, J. (2007). A study for standardization and validation of $K-C B C L$ 1.5-5. Poster session presented at the International Conference of the Cognition, Consciousness, and Culture, Seoul, Korea.

Seo, M. O. (2004). A validation of the Korean version of the Social Skill Rating System for preschool level (K-SSRS: Teacher and Parent Forms). Journal of Early Childhood Education, 24(2), 223-242.

\section{ORCID}

Soo Jung Kim http://orcid.org/0000-0003-3521-8360

Ick-Joong Chung http://orcid.org/0000-0002-3426-7956

Received February 23, 2018

Revision received March 31, 2018

Accepted April 16, 2018 